\title{
Powdered keramsite as unconventional method of AGS technology support in GSBR reactor with minimum-optimum OLR
}

\author{
Joanna Czarnota ${ }^{1, *}$, Adam Masłoń ${ }^{1}$, and Monika Zdeb ${ }^{2}$ \\ ${ }^{1}$ Rzeszow University of Technology, Department of Environmental Engineering and Chemistry, al. \\ Powstańców Warszawy 6, 35-959 Rzeszów, Poland \\ ${ }^{2}$ Rzeszow University of Technology, Department of Water Purification and Protection, al. \\ Powstańców Warszawy 6, 35-959 Rzeszów, Poland
}

\begin{abstract}
Aerobic Granular Sludge (AGS) technology becomes a very competitive method to activated sludge system. Its main advantages include: high energy efficiency and low investment costs. Despite this fact, intensive research on biogranulation optimization are still carried out, both at laboratory and technical scale. In order to intensify the AGS technology, new methods of biogranulation and ways of improving the stability of aerobic granules are sought. So far, several studies have been conducted in this area, with using among others: chemical coagulants, dosage fragments of granules and powdered materials. The aim of this study was to evaluate the impact of powdered keramsite on the feasibility of rapid aerobic granulation in a GSBR reactor with a minimum-optimum organic loading rate (OLR). The research presents an effective way of cultivating stable aerobic granules in a Granular Sequencing Batch Reactor (GSBR) under specific technological parameters.
\end{abstract}

\section{Introduction}

In order to intensify the AGS technology, new methods of biogranulation and ways to improve the stability of aerobic granules are sought. Based on the available literature, it was stated that so far, the research has been carried out with the use of: chemical coagulants [1], dosage of granules fragments $[2,3]$, powdered sewage sludge [4] and powdered materials [5-13].

Triturated substances with a particle size of less than $300 \mu \mathrm{m}$, used in a wastewater technology, are called powdered materials. In the activated sludge technology, they can serve different yet complementary functions: as the ballast of sludge flocs that improves their structure and properties, as the sorbent of chemical substances found in wastewater and as the biomass microcarrier [14]. On the other hand, in the aerobic granular sludge technology, powdered materials are the microcarrier of biomass which forms a granule [7]. The use of those materials allow to shorten the granulation time of activated sludge, because they act as a nucleus which induces the aggregation of microorganisms [4]. What is

${ }^{*}$ Corresponding author: askalucz@prz.edu.pl 
more, powdered materials used in the process move in the reactor with the granular sludge, this movement is caused by the air and liquid flows in the reactor. Powdered materials contribute to an increase in the collision and friction with aggregates of microorganisms. This can play an important role in the formation of the granules surface [4]. Divalent cations contained in powdered materials can participate in forming the matrix of aerobic granules [15].

Until now, research on supporting biogranulation by powdered materials in reactors with aerobic granular sludge has been performed using:

- mineral materials: basalt, bivalve shell carrier, zeolite, yellow earth [6-9, 12],

- materials of organic origin: granular activated carbon (GAC), powdered activated carbon (PAC) and dry sewage sludge micropowder $[4,5,10,11,13]$ (Table 1).

Table 1. Characteristics of powdered materials used in AGS technology [14].

\begin{tabular}{|c|c|c|c|}
\hline Material & $\begin{array}{c}\text { Diameter } \\
{[\mu \mathrm{m}]}\end{array}$ & $\begin{array}{c}\text { Density } \\
{\left[\mathrm{g} / \mathrm{cm}^{3}\right]}\end{array}$ & $\begin{array}{c}\text { Specific } \\
\text { surface area } \\
{\left[\mathrm{m}^{2} / \mathrm{g}\right]}\end{array}$ \\
\hline bivalve shell carrier & $150-220$ & 1.45 & large $^{(*)}$ \\
\hline basalt & $212-300$ & n.d. & large $^{(*)}$ \\
\hline zeolite & $150-300$ & n.d. & large $^{(*)}$ \\
\hline granular activated carbon & mean size 224 & 1.183 & 1002 \\
\hline granular activated carbon & 200 & $1.11-1.27$ & $495-567$ \\
\hline $\begin{array}{c}\text { dry sewage sludge } \\
\text { micropowder }\end{array}$ & $20-250$ & n.d. & n.d. \\
\hline yellow earth & above 270 & n.d. & n.d. \\
\hline
\end{tabular}

n.d. - no data

${ }^{(*)}$ numerical value has not been given in paper, only term "large" was used

Powdered materials, applied in the AGS technology, should:

- have a spherical shape,

- be heavy enough,

- be steadily suspended with biomass,

- sediment quickly,

- have a large specific surface area [14].

It should be noted that in systems to which powdered materials were applied, different technological parameters were adopted, both when it comes to the main parameters, such as configuration of the reactor and shear forces, and to the secondary parameters, such as hydraulic retention time (HRT) and volumetric exchange ratio (VER). A comparison of these parameters is presented in a paper by Czarnota et al. [14].

The use of powdered materials in the aerobic granular sludge technology can have numerous benefits, including greater properties of granules and better sedimentation characteristics. It is assumed that powdered materials accelerate the biogranulation process, decrease the concentration of a suspended matter at the outlet, have an impact on reducing the value of a sludge volume index and improve the stability of granules during a prolonged operation of the system [4-11] (Table 2). The application of these materials has an influence on the density of granules as well. Wei et al. [10] observed that the density of granules for a reactor with powdered activated carbon was $1.070 \mathrm{~g} / \mathrm{cm}^{3}$, while for a reference system without the powdered material, it was approximately $1.025 \mathrm{~g} / \mathrm{cm}^{3}$. What is more, after fifty days of operation, granules in the reference reactor broke up. Just for a comparison - the density of activated sludge is $1.0008 \mathrm{~g} / \mathrm{cm}^{3}[10]$. 
Table 2. Properties of granular sludge in systems with and without the addition of a powdered substance [14].

\begin{tabular}{|c|c|c|c|c|c|}
\hline $\begin{array}{c}\text { System with powdered } \\
\text { substance }\end{array}$ & \multirow{2}{*}{$\begin{array}{l}\text { Dosage of } \\
\text { substance } \\
{\left[\mathrm{g} / \mathrm{dm}^{3}\right]}\end{array}$} & \multirow{2}{*}{$\begin{array}{c}\mathrm{COD} \\
{\left[\mathrm{mg} \mathrm{O}_{2} / \mathrm{dm}^{3}\right]}\end{array}$} & \multirow{2}{*}{$\begin{array}{l}\text { Diameter } \\
\text { of granules } \\
{[\mathrm{mm}]}\end{array}$} & \multirow{2}{*}{$\begin{array}{l}\text { MLSS } \\
{\left[\mathrm{g} / \mathrm{dm}^{3}\right]}\end{array}$} & \multirow{2}{*}{$\begin{array}{c}\text { SVI } \\
{\left[\mathrm{cm}^{3} / \mathrm{g}\right]}\end{array}$} \\
\hline Reference system & & & & & \\
\hline \multirow{2}{*}{$\begin{array}{l}\text { bivalve shell carrier } \\
\text { anaerobic granule }\left(35 \mathrm{~cm}^{3}\right)\end{array}$} & 20.0 & \multirow{2}{*}{$\begin{array}{c}600 \\
2.5-30.0^{(*)}\end{array}$} & $0.5-2.0$ & about 10 & 14.0 \\
\hline & - & & $0.3-4.0$ & about 15 & 19.0 \\
\hline reactor SBAR + basalt & 20.0 & \multirow{2}{*}{$3.0-4.0^{(*)}$} & $0.3-3.7$ & 11.23 & $24-32$ \\
\hline reactor SBBR + basalt & 20.0 & & $0.3-4.0$ & 12.78 & $21-28$ \\
\hline zeolite & 3.0 & \multirow{2}{*}{$800-2000$} & $1.0-5.0$ & 7.36 & 34.9 \\
\hline without powdered substance & - & & $0.6-4.0$ & 5.45 & 47.9 \\
\hline powdered activated carbon & 1.0 & \multirow{2}{*}{$1310-5534$} & to 0.6 & 5.0 & 38.0 \\
\hline without powdered substance & - & & to $0.7^{(* *)}$ & - & - \\
\hline granular activated carbon & 3.0 & \multirow{2}{*}{$\begin{array}{l}200 \\
0.8^{(*)}\end{array}$} & to 0.6 & about 3.4 & 40.0 \\
\hline without powdered substance & - & & to 0.25 & about 3.0 & 100.0 \\
\hline granular activated carbon & 1.0 & \multirow{2}{*}{$\begin{array}{c}503 \pm 25 \\
1.5^{(*)}\end{array}$} & 0.44 & 9.08 & 26.0 \\
\hline without powdered substance & - & & absence & 3.50 & 70.0 \\
\hline sewage sludge micropowder & 1.0 & \multirow{2}{*}{$\begin{array}{c}800-1000 \\
4.0^{(*)}\end{array}$} & about 0.4 & 8.62 & 51.0 \\
\hline without powdered substance & - & & about 0.2 & 4.92 & 73.0 \\
\hline
\end{tabular}

${ }^{(*)}$ organic loading rate $\left[\mathrm{g} \mathrm{COD} /\left(\mathrm{dm}^{3} \cdot \mathrm{d}\right)\right]$

${ }^{(* *)}$ breakup of granules

The aerobic granular sludge technology facilitates the removal of carbon, nitrogen and phosphorus compounds in a single reactor which, works as a sequencing batch reactor. The removal of contaminants is enabled by the stratification of transition processes and the presence of a redox potential within granules, which is provided by presence of aerobic and anaerobic/anoxic layers [14]. The research conducted so far has showed that the support of aerobic sludge biogranulation process by powdered materials helps boost the efficiency of organic compounds, nitrogen and phosphorus removal from wastewater.

\section{Materials and method}

The research was performed on a laboratory scale. Aerobic granules were cultivated in two identical GSBRs (Granular Sequencing Batch Reactor). Reactor R1 was a reference system and powdered keramsite was applied to reactor R2 (Fig. 1). Each reactor had a working volume of $3.0 \mathrm{dm}^{3}$ with an internal diameter and working height of $0.07 \mathrm{~m}$ and $0.78 \mathrm{~m}$, respectively. The technological parameters of the system are presented in Table 3 . The reactors operated in successive cycles of 3 hours each, including feeding without stirring (10 min), reaction - aeration (160 min), settling (4 min), decantation (5 min) and idle phase $(1 \mathrm{~min})$. Air used in the reaction phase (aeration) was introduced through a fine bubble air diffuser at the bottom of the reactor. A rotameter was used to adjust the air flow velocity and maintain the flow at a constant level of $0.8 \mathrm{~cm} / \mathrm{s}$. In the research, synthetic wastewater was used (prepared according to the chemical composition given by Thanh [15]) and glucose was a source of organic compounds. The influent COD concentration of the two reactors was $717.1 \pm 62.6 \mathrm{mg} \mathrm{O} / \mathrm{dm}^{3}$, and the organic loading rates (OLR) was about $2.55 \mathrm{~g} \mathrm{COD} /\left(\mathrm{dm}^{3} \cdot \mathrm{d}\right)$, which is the minimum value of the load considered as optimal for the AGS technology [16]. 


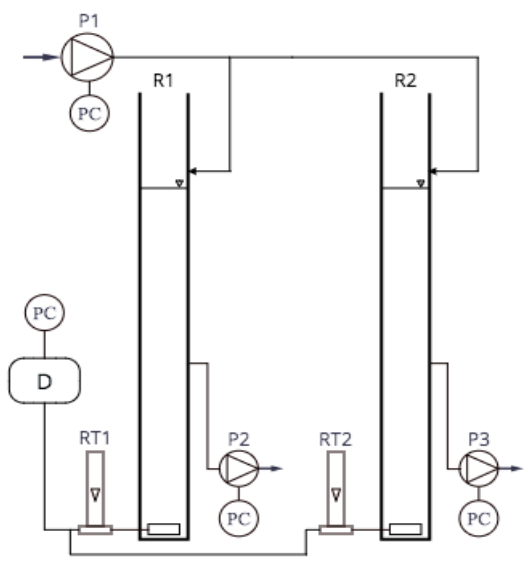

Fig. 1. Schematic diagram of the experimental set-up: P1 - feeding pump, P2-P3 - effluent pump, RT1-RT2 - rotameter, PC - control panel, D - air blower.

Table 3. Technological parameters of the reactors in the research.

\begin{tabular}{|c|c|c|c|}
\hline \multirow{2}{*}{ Parameter } & \multirow{2}{*}{ Unit } & \multicolumn{2}{|c|}{ Reactor } \\
\cline { 3 - 4 } & & $\mathrm{R} 1$ & $\mathrm{R} 2$ \\
\hline average daily flow of wastewater & {$\left[\mathrm{dm}^{3} / \mathrm{d}\right]$} & 12.0 & 12.0 \\
\hline volumetric exchange ratio $(\mathrm{VER})$ & {$[-]$} & 0.5 & 0.5 \\
\hline amount of wastewater fed during the cycle $(\Delta \mathrm{V})$ & {$\left[\mathrm{dm}^{3}\right]$} & 1.5 & 1.5 \\
\hline hydraulic retention time $(\mathrm{HRT})$ & {$[\mathrm{h}]$} & $6^{(*)}$ & 6 \\
\hline air supply & {$\left[\mathrm{dm}^{3} / \mathrm{h}\right]$} & 110 & 110 \\
\hline dosage of powdered keramsite & {$\left[\mathrm{g} / \mathrm{dm}^{3}\right]$} & - & 3.0 \\
\hline
\end{tabular}

${ }^{(*)}$ it was necessary to control the value of HRT in order to control the biomass concentration in the reactor

Activated sludge from a nitrification tank of a wastewater treatment plant in Rzeszow was used as the seed sludge. After inoculation of the system with the activated sludge and its adaptation period, physico-chemical analyses of the raw and treated wastewater were performed (COD, TN, N-NH$\left.{ }^{+}, \mathrm{N}_{-} \mathrm{NO}_{3}{ }^{-}, \mathrm{N}-\mathrm{NO}_{2}{ }^{-}, \mathrm{TP}, \mathrm{P}-\mathrm{PO}_{4}{ }^{3-}\right)$. At the same time, several parameters were determined, including biomass concentration (MLSS), mixed liquor volatile suspended solids (MLVSS), sludge volume index after 5 minutes $\left(\mathrm{SVI}_{5}\right)$ and after 30 minutes $\left(\mathrm{SVI}_{30}\right)$ of sedimentation, and the sludge settling velocity (SV). The aforementioned parameters were analysed according to the standard methods. The morphology of the sludge flocs and the aerobic granules was observed under an optical microscope (Olimpus BX51). The size of the aerobic granules was determined according to a method proposed by Arrojo [17], using a specialized software CellQ.

Powdered keramsite is a material with a natural grain size in the grain class from 0 to $200 \mu \mathrm{m}$. The material that was used in the study had a specific surface area of $5.183 \mathrm{~m}^{2} / \mathrm{g}$, an apparent density of $2.6182 \mathrm{~g} / \mathrm{cm}^{3}$ and a settling velocity of particles varying in size from 100 to $200 \mu \mathrm{m}$ of approx. $9.0 \mathrm{~m} / \mathrm{h}$.

\section{Results and discussion}

The COD loading for each reactor, taking into consideration technological parameters that were adopted, was $2.55 \pm 0.22 \mathrm{~g} \mathrm{COD} /\left(\mathrm{dm}^{3} \cdot \mathrm{d}\right)$. According to data found in literature, the 
optimal OLR of a GSBR reactor should be from 2.50 to $7.50 \mathrm{~g} \mathrm{COD} /\left(\mathrm{dm}^{3} \cdot \mathrm{d}\right)$. Under these conditions, the biogranulation of sludge is possible and granules are characterized by a compact structure [16]. A short settling time adopted in the study encouraged the wash out of the biomass from the reactors. The initial MLSS concentration (after the inoculation of the reactors) in both reactors was $3.90 \mathrm{~g} / \mathrm{dm}^{3}$ and after the application of powdered keramsite to reactor R2, the value increased to $7.38 \mathrm{~g} / \mathrm{dm}^{3}$. During the adaptation period of the system, the concentration of MLSS in the reactors decreased by $46 \%$ and $43 \%$, whereas the concentration of MLVSS decreased by $44.5 \%$ and $22 \%$. After 5 days, the MLSS values in R2 increased and the average value of this parameter was $5.24 \pm 0.78 \mathrm{~g} / \mathrm{dm}^{3}$. The results showed in Fig. 2 show a better retention of the biomass in R2, compared to R1 (less sludge was washed out from R2 than R1). The average amount of suspended solids in the effluent was $90 \mathrm{mg} / \mathrm{dm}^{3}$ (generally $70 \mathrm{mg} / \mathrm{dm}^{3}$ ) in the R2, this value is lower than in the R1 - 140 $\mathrm{mg} / \mathrm{dm}^{3}$. After 19 days, the ratio of MLVSS to MLSS in the reference reactor increased from 0.44 to 0.77 , while in the reactor with powdered keramsite, the MLVSS/MLSS ratio after the $12^{\text {th }}$ day varied between 0.76 and 0.84 . This indicates a higher bioactivity and a lower inorganic composition of granular sludge, compared to flocs (Fig. 2).

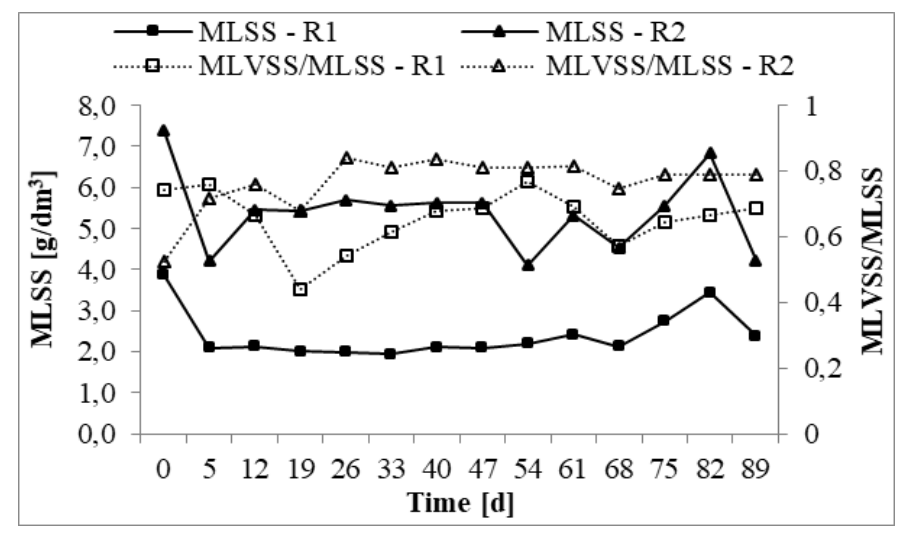

Fig. 2. Profile of MLSS and MLVSS/MLSS.

Furthermore, by analysing the sedimentation properties of the sludge, defined on the basis of the quotient values for $\mathrm{SVI}_{5} / \mathrm{SVI}_{30}$, from $19^{\text {th }}$ day of the research, it was noted that significantly lower values were observed in the reactor with a powdered material (Fig. 3).

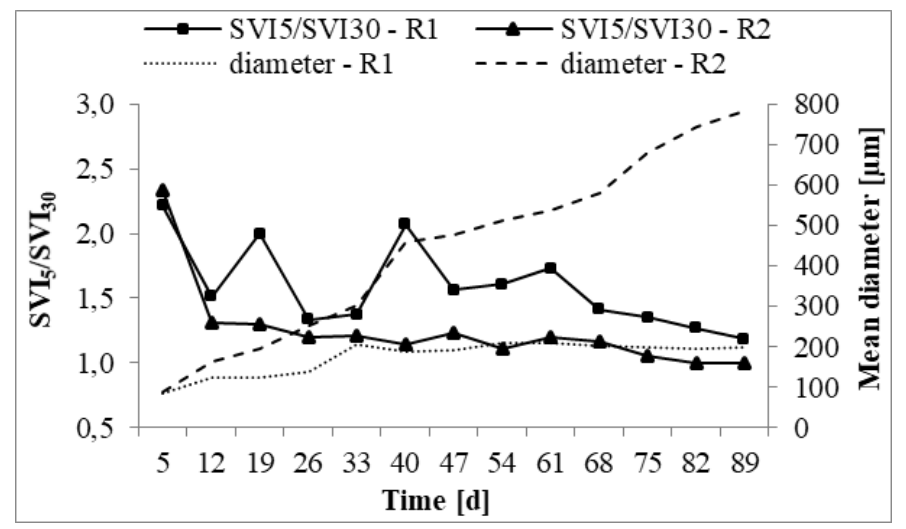

Fig. 3. The $\mathrm{SVI}_{5} / \mathrm{SVI}_{30}$ ratios and granule size development in reactors during research.

The values for $\mathrm{SVI}_{5} / \mathrm{SVI}_{30}$ in $\mathrm{R} 2$ showed that the addition of powdered keramsite could have an apparent influence on the improvement of sludge compressibility and settling 
capacity. The initial $\mathrm{SVI}_{5}$ values were 240.3 and $116.5 \mathrm{dm}^{3} / \mathrm{g}$, while $\mathrm{SVI}_{30}$ values were 152.5 and $52.2 \mathrm{dm}^{3} / \mathrm{g}$, respectively in R1 and R2. At the end of the study, $\mathrm{SVI}_{5}$ values in the GSBR reactors were 108.8 and $30.7 \mathrm{dm}^{3} / \mathrm{g}$, while $\mathrm{SVI}_{30}$ values were 92.1 and $30.7 \mathrm{dm}^{3} / \mathrm{g}$, respectively. The $\mathrm{SVI}_{30}$ values in GSBR with keramsite were much lower than $150 \mathrm{dm}^{3} / \mathrm{g}$ for the activated sludge. The results of the study comply with the outcomes of the research by Li et al. [5] who found that the sludge in the reactor with an initial GAC addition had a lower $\mathrm{SVI}_{30}$ value than the one without GAC during the whole process.

In the consecutive days of the study, good sedimentation properties of biomass along with an increase in the contribution of granules and their higher settling velocity were observed in R2. The dynamics of the sludge growth is shown in Fig. 3. The analysis of granules size distribution showed that the mean granule size in R2 increased from $89.3 \mu \mathrm{m}$ to $251.9 \mu \mathrm{m}$ at day 29, and a complete granulation was achieved in R2 with the mean granule sizes of $511.3 \mu \mathrm{m}$, with no apparent increase of granules size in the R1. As an example, within 14 days from the acclimation, the size of the sludge in R2 showed a growing tendency and the mean floc size increased to $194.1 \mu \mathrm{m}$, while in R1, the mean floc size was $123.1 \mu \mathrm{m}$. However, the cumulative volume percentages of granules with the diameter over $200 \mu \mathrm{m}$ in both reactors were $9.38 \%$ and $38 \%$, respectively, indicating that the filamentous sludge was still the dominant form of the biomass in both reactors. After 89 days of operation, the mean granules size reached $200.2 \mu \mathrm{m}$ in R1 and $783.1 \mu \mathrm{m}$ in R2. At the end of the study, the average size of granules in R2 was four times higher than in R1 (Fig. 4).

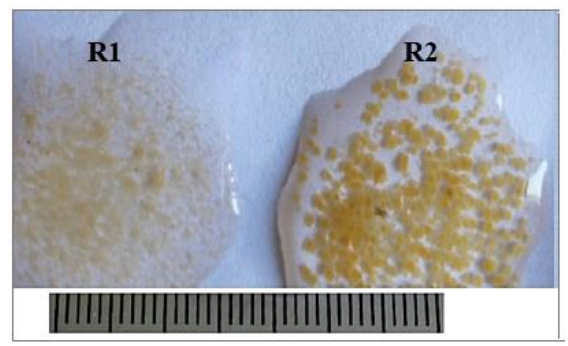

Fig. 4. Photography of the biomass in reactors after 89 days of operation.

The comparative results demonstrate that the initial addition of powdered keramsite was crucial to the formation of granules in R2. In other words, the aerobic granulation would not have been achieved under technological parameters adopted in the study without the addition of the powdered material during the GSBR start-up.

The settling capacity and compressibility of the sludge improved significantly with aerobic granulation in R2. The average settling velocity of mature granules from the reactor with powdered keramsite was $15.4 \pm 6.1 \mathrm{~m} / \mathrm{h}$, which is much faster than the settling velocity of sludge flocs in R1 $(4.0 \pm 0.4 \mathrm{~m} / \mathrm{h})$. The powdered material in R2 supported the formation of larger granules with a better settling capacity of the biomass. Thanh et al. [8] showed that in system with an OLR of $5.0 \mathrm{~g} \mathrm{COD} /\left(\mathrm{dm}^{3} \cdot \mathrm{d}\right)$ the biomass had a settling velocity of almost $70 \mathrm{~m} / \mathrm{h}$ in the reactor with the powdered material, and the velocity was three times lower in the reference reactor. These values are much higher comparing to the settling velocity of the ordinary activated sludge which is $1-2 \mathrm{~m} / \mathrm{h}$.

The COD removal efficiency is presented in Fig. 5. It was $77.4 \pm 11.1 \%$ for R1 and $85.4 \pm 5.4 \%$ for R2, which means that the reduction of COD in wastewater reached $90.8 \%$ in the reference system and $94.8 \%$ in the system supported by keramsite. The values obtained for R2 were similar to the results reported by Minh [6] for a reactor supported by basalt (78-97\%) and higher than the results reported by Wei [10] for a reactor supported by powdered activated carbon (about 65\%). The concentration of organic compounds was 
lower in the effluent for R2. In the reactor with the powdered material, a clear correlation was observed between an increasing efficiency in the reduction of COD and the growth of the OLR of the reactor.
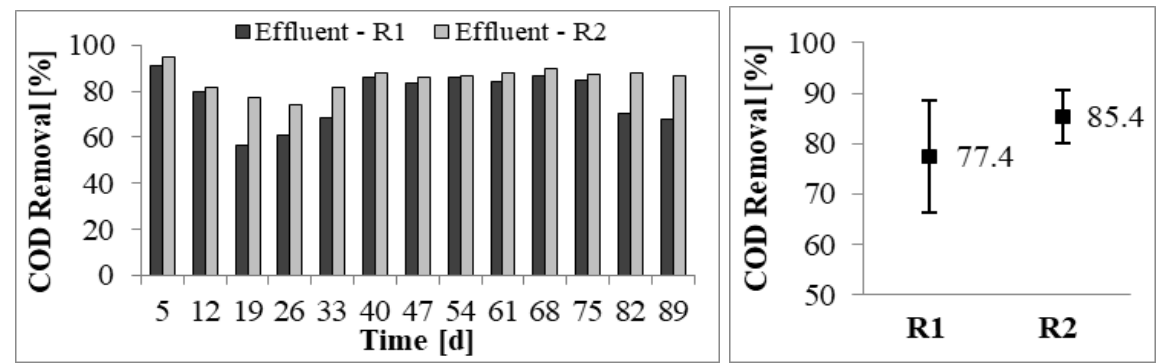

Fig. 5. COD removal efficiency in reactors.

The maximum efficiency of TN removal achieved in the study was $72.3 \%$ in R1 and $77.3 \%$ in R2, but the average values stood at $41.9 \pm 17.7 \%$ and $56.6 \pm 10.2 \%$, respectively for R1 and R2 (Fig. 6). The results obtained in R2 are comparable to the data presented by Tao et al. [13] $\left(60 \%\right.$ for $\mathrm{TN}, 100 \%$ for $\left.\mathrm{N}-\mathrm{NH}_{4}{ }^{+}\right)$. In the studies by Zhou et al. [11], the effectiveness of TN removal was $72.5 \%$ for a reactor to which GAC with a particle size of $0.2 \mathrm{~mm}$ was added. It should be noted that the efficiency of ammonium nitrogen removal was very high in $\mathrm{R} 2(95.1 \pm 12.8 \%)$, while about $78.7 \pm 17.0 \% \mathrm{~N}_{-} \mathrm{NH}_{4}{ }^{+}$was eliminated in $\mathrm{R} 1$.
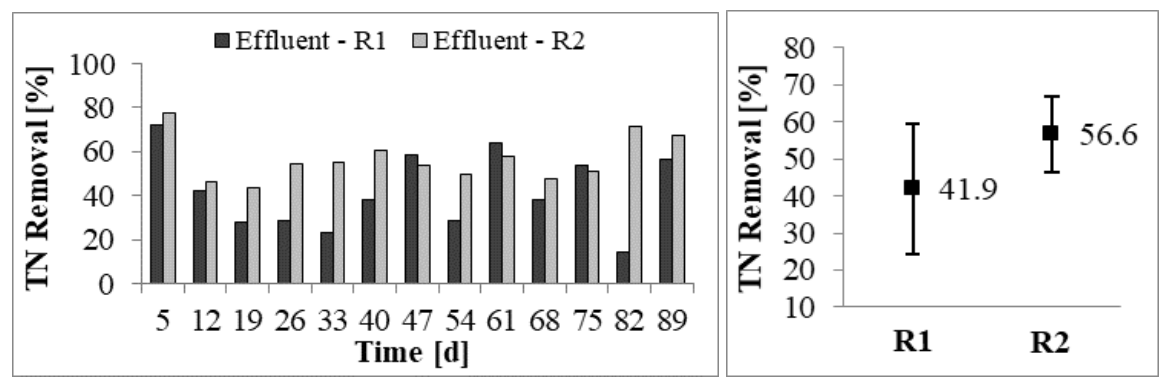

Fig. 6. TN removal efficiency in reactors.

The biggest differences were observed in total phosphorus removal: max. 59.7\% in R1 and $75.5 \%$ in R2. The average values amounted to $31.5 \pm 19.8 \%$ and $56.8 \pm 9.9 \%$, respectively in R1 and R2 (Fig. 7).
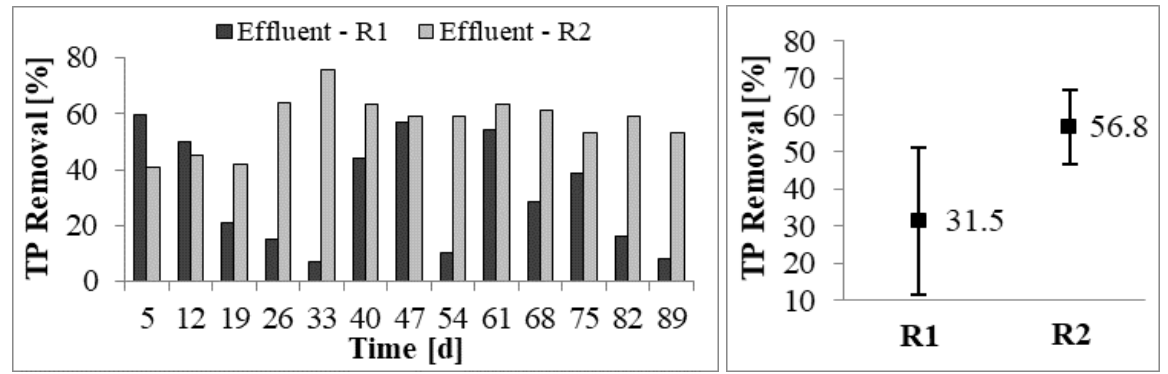

Fig. 7. TP removal efficiency in reactors.

Values obtained for R2 were higher than the results presented by He et al. [12] (17-46\%) for a reactor working without the anaerobic phase and supported by yellow earth. Tao et al. [13] obtained a higher TP removal rate (15-99\%), but researchers added an anaerobic phase in the operating cycle of the reactor ( $99 \mathrm{~min})$, which was supported by GAC. 


\section{Conclusions}

In the context of the challenges which the wastewater treatment technology based on granular sludge has to face, it is appropriate to take further actions in order to evaluate the effectiveness of supporting the aerobic granular sludge technology by powdered materials. The currently available publications indicate that powdered materials have a positive impact on the biogranulation process, help accelerate the aggregation of microorganisms, and lead to the formation of mature granules in a short time. What is more, they enhance the sedimentation properties of aggregates obtained in the process. The research presented herein proved that the powdered material has a relevant impact on the formation of granules under specific operating parameters in reactors (a lower wash out level of the biomass, a higher concentration of the biomass). The use of keramsite had a positive impact on the sedimentation properties of the sludge and the efficiency of the wastewater treatment. The results showed that granules could not be formed in GSBR without powdered keramsite. A complete granulation was only achieved in GSBR with a powdered keramsite addition. The material that was used served as the ballast of sludge flocs used as the seed sludge, and as the microcarrier of biomass which forms a granule.

\section{References}

1. A. Val del Río, N. Morales, M. Figueroa, A. Mosquera-Corral, J.L. Campos, R. Méndez, J. Chem. Technol. and Biotechnol. 87, 908-913 (2012)

2. M. Pijuan, U. Werner, Z.G. Yuan, Water Res. 45, 5075-5083 (2011)

3. M. Verawaty, M. Pijuan, Z.G. Yuan, P.L. Bond, Water Res. 46, 761-771 (2012)

4. J. Li, J. Liu, D. Wang, T. Chen, T. Ma, Z. Wang, W. Zhuo, Int. J. Environ. Res. Public Health 12, 10056-10065 (2015)

5. A.J. Li, X.Y. Li, H.Q. Yu, Sep. Purif. Technol. 80, 276-283 (2011)

6. N.D. Minh, AIT Thesis, 1-119 (2006)

7. B.X. Thanh, Ch. Visvanathan, R.B. Aim, Process Biochem. 44, 242-245 (2009)

8. B.X. Thanh, Ch. Visvanathan, R.B. Aim, J. Membrane Sci. 318, 334-339 (2008)

9. D. Wei, X. Xue, S. Chen, Y. Zhang, L. Yan, Q. Wei, B. Du, Appl. Microbiol. Biotechnol. 97, 9235-9243 (2013)

10. Y. Wei, M. Ji, G. Li, F. Qin, $2^{\text {nd }}$ Conference ESIAT, 805-808 (2010)

11. J. Zhou, H. Zhao, M. Hu, H. Yu, X. Xu, J. Vidonish, Bioresour. Technol. 198, 358-363 (2015)

12. Q.L. He, S.L. Zhang, Z.C. Zou, H.Y. Wang, WRE 2016 IOP Conf. Series: Earth and Environmental Science 39, 1-10 (2016)

13. J. Tao, L. Qin, X. Liu, B. Li, J. Chen, J. You, Y. Shen, X. Chen, Bioresour. Technol. 236, 60-67 (2017)

14. J. Czarnota, J.A. Tomaszek, A. Masłoń, GWiTS 11, 407-412 (2016)

15. B.X. Thanh, AIT Thesis No. EV-05-5, 1-157 (2005)

16. P. Augustyniak, J. Podedworna, II Ogólnopolska Konferencja Naukowa nt. Gospodarka wodno-ściekowa i odpadowa miast i obszarów niezurbanizowanych, Tleń (2015)

17. B. Arrojo, PhD Thesis, University Santiago de Compostela, 1-312 (2007) 